\title{
Factors Influencing Prescribing Perceived Utility of Drugs: Experiences from Iraqi Kurdistan
}

Deldar Morad Abdulah, Master in Public Health ${ }^{1}$; Karwan Ali Perot, Master of Business and Management ${ }^{2}$

${ }^{1}$ Adult Nursing Department, College of Nursing, University of Duhok Iraq

${ }^{2}$ School of Health and Environmental Sciences, Auckland University of Technology, New Zealand and Kurdistan Business School, University of Kurdistan- Hewler, Iraqi Kurdistan

\begin{abstract}
Introduction: Pharmaceutical expenditures have increased dramatically in most developed and developing countries in recent decades. Healthcare system policymakers have expressed concerns about the inappropriate, irrational, or harmful prescribing of drugs.

Objectives: The attitudes of physicians towards prescribing generic drugs and predictors of perceived utility of drugs were investigated in the present study. Methods: In this cross-sectional research, 77 physicians at different levels of job hierarchies, working in various public sector shifts, were recruited to participate in a survey of their attitudes toward prescribing generic drugs in Iraqi Kurdistan in 2018. The doctors were located in a general, an emergency, and a pediatric hospital. A self-administered structured questionnaire was designed based on the extended technology acceptance model for product use (TETPU). Results: The doctors agreed that drugs should be prescribed according to their utility for patients (median $[M]=5.0$; interquartile range $[I Q R]=2.9$ ). Most of the physicians mentioned that they prescribed drugs according to the patients' needs (75.0\%), evaluation of the availability of alternatives (69.0\%) and consumer perceptions of a price (69.0\%). The analysis showed that (1) the importance of physicians' perceptions and their recognition of patients' need achievement $(P=.012)$, (2) the physicians' recognition of the actual use of drugs by consumers $(P=.030)$ and $(3)$ being male $(p=.009)$ were associated with perceptions of drug utility. Conclusions: The study's results suggest that perceived drug utility in prescription writing is associated with physicians' perceptions of need achievement and attitudes toward how patients actually use medicines.
\end{abstract}

Keywords: Prescription; drug administration; doctors' attitudes; perceived utility

\section{Introduction}

Pharmaceutical expenditures have increased dramatically in most developed and developing countries in recent decades and has raised concerns among healthcare policymakers about health systems' sustainability. ${ }^{-}$The Organization for Economic Cooperation and Development (OECD) has ranked pharmaceutical costs third among the largest medical expenditures, after inpatient and outpatient care, with prescribed drugs accounting for $17 \%$ of health expenditures across OECD countries in 2013. Hospitals' pharmaceutical costs were not considered in this statistic. $\underline{2}$ Healthcare system policymakers have thus expressed deep concern about inappropriate, irrational, or harmful drug prescribing. $\underline{3}$

Observational and experimental studies have found evidence that many patients are not always prescribed the best pharmaceutical therapies for their medical conditions. $4, \underline{5}$ In addition, the overuse and misuse of pharmaceutical products has been substantiated. $\stackrel{4}{\underline{5}}$ This trend could result in patients' loss of health and quality of life and lead to increased healthcare expenditures and adverse events. $\underline{6}$

Using generic drugs is increasing in most countries worldwide to reduce health-associated costs. $\underline{7}$ In mature healthcare systems, physicians urge their patients to use generic drugs

Corresponding author: Deldar Morad Abdulah, Master in Public Health, Adult Nursing Department, College of Nursing, University of Duhok, Iraqi Kurdistan

Email: deldarmorad@gmail.com; Phone: +9647507443319 irrespective of their socioeconomic status or healthcare systems' policies. $\stackrel{8}{\text { In }}$ developed countries, physicians have positive perceptions, whereas those from low and middleincome countries (LMIC) have mixed views about generic medicines. $\stackrel{9}{ }$ In Iraq, some physicians are against prescribing generic medicines, while others are more open-minded. $\underline{10}$ Therefore, the recommended optimal and established guidelines for prescribing generic drugs must be examined and monitored throughout the health sector. More specifically, the prohibition of dispensing medicines without prescriptions is poorly enforced in Iraqi Kurdistan. $\underline{11}$ In addition, some generic drugs do not need a standardized written form. In Iraqi Kurdistan, the doctors are affected by receiving promotional materials and activities to prescribe a new drug, including medical samples $(67.8 \%)$; funding of registration costs to conferences $(60.1 \%)$; participation in industry-funded researches (69.9\%); and continuing medical education $(69.4 \%) . \underline{12}$

Various studies have sought to examine and interpret the factors that influence the behaviors and practices of physicians regarding prescribing drugs. In the past, many factors have been reported in the literature as having a role in tendencies of doctors to prescribe drugs. $\underline{13-15}$ Some factors cannot be changed, and they do not offer opportunities to make modifications or improvements, including gender, age, socioeconomic characteristics, and drug therapies' reimbursement status. $\underline{16}, \underline{17}$ Other factors have changed over time, and they can produce modifications in behaviors of 
physicians to prescribe a drug. The latter factors include, among others, doctors' medical experience, education level, and social factors. $\underline{18}$

Further factors affecting doctors to prescribe a particular drug are "opinion leaders" and medical specialists' behaviors in medical networks. $\frac{19}{}$ Opinion leaders' significant role in deciding patterns of prescribing drugs has been reported by various investigators. $\underline{20}, \underline{21}$ In addition, free drug samples given to physicians with varied levels of experience have been shown to have an impact on prescription generation. $\underline{22}$ Tan and colleagues $^{23}$ reported that medical training, patient factors, drug costs, and disease definition in primary health systems play a role in family physicians' patterns of prescribing asthma drugs.

A study conducted in Greece and Cyprus showed that clinical effectiveness is a factor given significant weight in prescribing drugs. Generic drugs' safety and efficacy were not considered crucial factors by physicians in these two countries. $\frac{24}{}$ Generic drug products are defined as interchangeable with brand pharmaceuticals. The former is manufactured with a license obtained after the expiration of drugs' patent and exclusive rights..$\underline{5}$

Policymakers rely on existing investigations to determine the measures needed to enhance health policies' effectiveness and ensure greater economic and clinical efficiency. Notably, no prior study has specifically focused on predictors of doctors' perceptions of drug utility, which is one of the most important factors in prescribing drugs. The definition of perceived utility was adapted from Sanyal et al. ${ }^{26}$ They mentioned that "perceived utility of generic drugs refers to the physicians' overall assessment of the utility based on the perceptions of what is actually obtained from generic drugs, easy availability, the effectiveness of physician job and the satisfaction of physicians' needs for better quality."

To fill this research gap, the current study explored the attitudes of physicians towards prescribing generic drugs. In addition, predictors of the perceived utility of generic drugs were examined in the context of prescribing generic drugs for an Iraqi Kurdistan physician's sample.

\section{Methods}

\section{Study design and subjects}

In this cross-sectional study, 142 physicians with different levels of education and medical experience were contacted through the relevant clinical department secretary. The doctors had different specialties and worked in three public hospitals: a general, an emergency, and a pediatric facility. These hospitals with various specialties were included in the study to cover different physicians' attitudes. Only doctors who could prescribe drugs were invited, so the respondents did not belong to specialties such as radiology, microbiology, hematology, forensic medicine, and anesthesiology. In line with the research objectives, the doctors were selected from different shifts and clinical settings. Since the respondents' work shifts were changeable, the sample could not be selected randomly.

Of the total 142 invited physicians, 86 of them returned the questionnaire yielding a response rate of $60.6 \%$. Nine physicians did not complete the whole questionnaire, so they were excluded from the data analyzed. In addition, 56 doctors did not participate due to their workloads and therapeutic procedures.

We expected that the physicians might have not sufficient information and experience about new generic drugs (the generic drugs were entered into the pharmaceutical market for the last three years). Therefore, the respondents were not requested to report on their attitudes toward prescribing new drugs.

The time required to fill out the entire questionnaire was 10 minutes. The study was conducted in three hospitals in Erbil/Iraqi Kurdistan between October and November 2018. The participation of the subjects was optionally and anonymously.

\section{Data collection and measurement}

The doctors' general information was gathered with a selfadministered questionnaire, including age, gender, and placement in job hierarchies. The latter included the categories of junior house officer, senior house officer, general practitioner, specialist, and consultant. In addition, items asked the respondents to be specific if they work in the public, private, or both sectors and work mornings ( 8 a.m. -2 p.m.), evenings ( 2 p.m. -8 p.m.), nights ( 8 p.m. -8 a.m.), or multi-shift schedules (i.e., in line with the local health system). The demographic data were used as confounders to obtain more robust assessments of the doctors' perceptions of generic or branded generic drugs.

A structured questionnaire based on the extended technology acceptance model for product usage (TETPU) was used to measure the physicians' attitudes toward prescribing generic drugs. The measurement instrument has been developed according to the strategic, comprehensive model. $\underline{27}$ The TETPU model is based on the strategic, comprehensive branding model. .27 The constructs were used to establish this model were product brand equity, corporate brand equity, perceived cost, perceived utility, opinion leaders, availability of alternatives, brand age, perceived no need, physicians; physicians' perception and need achievement, physicians' attitude, prescription intention, demographic variables, and actual use.

The constructs included in the present model were defined as follow:

Perceived utility: "Perceived utility of generic drugs referred to the physicians' overall assessment of the drug utility based on the perceptions of what is actually obtained from generic drugs, 
easy availability, the effectiveness of physician job and the satisfaction of physicians' needs for better quality". $\underline{28}$ The perceived utility was assessed with five items, namely, perceptions of prescribing drug according to drug efficacy, and generic drug tolerability, easy availability, patient satisfaction, and physicians' on-the-job effectiveness. Physicians' on-the-job effectiveness was defined as a clinical improvement as the result of prescribing a generic drug.

The perceived ease of use was considered to be redundant in explaining the prescribing attitude of the physicians in this model. $\underline{\underline{26}}$ Therefore, in line with the model, it was not included in the measurement.

Perceived no need: It was defined as a physician prescribes a drug to a patient when the patient needs it.

Availability of alternatives: It was defined as a physician prescribes a drug to the patient when evaluating the availability of drug alternatives.

Perceived cost: it was defined as a physician prescribes a drug to a patient when it considers the consumer's perceptions of a price.

Importance of product brand equity: it was defined as a physician who prefers a brand of drug to another one to prescribe it.

Importance of corporate brand equity: It was defined as the sustainability of a brand of a drug for the doctor to prescribe it. The features of the drug were not included in this item. The significant advantages of the drug were considered in corporate brands. The advantages were trust, loyalty, and scientific credibility for its research and development, credibility to its sales force and creation of a new product launching environment."

Importance of opinion leaders as communicators of the brand: it was defined as considering the opinion leaders in prescribing a generic drug. The leaders refer to health policymakers, hospital managers, or clinical supervisors.

Importance of physicians' perceptions and need achievement: It was referred to as the perception and recognition of the physicians of the patients' needs. In other words, the physician prescribes a drug based on the recognition of the patient's needs.

Importance of pharma brand age in brand awareness: It was referred to the importance of pharma brand age among customers.

Attitude toward branded generics: It was defined as a physician prescribes a drug to the patient according to the patients' attitudes towards drugs' favorability.
Prescription intention: it was defined as the physician recognized that a patient intended to purchase a drug.

Consumers' intentions/attitudes: It was defined as the physician considers the importance of the drugs to the patients.

Actual use of consumers: it was defined as the physician considers the actual use of the drugs by the patients to prescribe a drug. $\underline{26}$

The study questionnaire included the following sections:

Perceive utility: The physicians were asked to respond to the following question items when they prescribe the drugs to patients.

- I prescribe the drugs to patients according to their efficacy.

- I prescribe the drugs to patients according to the tolerability of the branded generics.

- I prescribe the drugs to patients according to easy availability.

- I prescribe the drugs to patients according to the patient's satisfaction.

- I prescribe the drugs to patients according to the effectiveness of the physician job.

Other factors: Some other question items were used to examine the doctors' attitudes towards prescribing drugs to the patients. The factors were:

- I prescribe the drugs according to the patients' needs.

- I prescribe the drugs to patients according to the evaluation of alternatives availability.

- I prescribe the drugs according to consumer perceptions of price.

- I prescribe the drugs according to product brand equity.

- I prescribe the drugs according to corporate brand equity.

- I prescribe the drugs according to opinion leaders' influence.

- I prescribe the drugs according to the importance of physicians' perceptions and need achievement.

- I prescribe the drugs according to the importance of the pharma brand age in brand awareness.

- I prescribe the drugs according to the importance of customers' attitudes towards drug's favorability.

- I prescribe the drugs according to consumers' intend to purchase.

- I prescribe the drugs according to the consumer's intentions/attitudes.

- I prescribe drugs according to the actual use of consumers.

The responses were given on a 7-point Likert scale $(1=$ "Strongly disagree"; 7 = "Strongly agree"). The scale's internal consistency reliability was confirmed with a Cronbach's alpha value of 0.767 for perceived utility and more than 0.700 for other items. The questionnaire was administered in the original language (i.e., English) to the respondents because schools' official language in the region under study is English. 


\section{Statistical analysis}

The normality of the participants' information including age and their attitudes towards drug prescription was tested in the Shapiro-Wilk test. The significant P-value of the result was considered to be non-normally distributed information. The doctors' attitudes toward prescribing generic drugs were quantified in terms of the median and interquartile range (IQR), while categorical variables were estimated by frequency and percentage.

The mean and standard deviation of five question items were measured to obtain the overall score of perceived utility. The perceived utility of prescribing generic drugs was transformed into a two-step to create a normally distributed dependent variable. Accordingly, the predictors of perceived drug utility among physicians were examined using either linear regression. The Box's $M$ test was performed for the independent variables $(P=0.286)$. Multivariate analysis was performed to examine the predictors of perceived utility question items. The null hypothesis was determined based on a $p$-value of less than 0.05 . The statistical calculations were performed using the IBM Statistical Package for Social Sciences version 25 software. A random sample could not be obtained from the target population as the doctors in question were not all present in one setting or shift, and some were not available during the data collection period due to their workloads and/or therapeutic, diagnostic, or surgical procedures.
The sample size was estimated using Slovin's formula as shown in Equation (1): $n=N /\left(1+N e^{2}\right)$

in which $n$ is the sample size, $N$ is the target population, and $e$ is an error tolerance of $5 \%$. The total number of doctors in the 3 hospitals who were eligible for the study was 220 . The total sample invited to participate in this research was 142 doctors. Of these, 86 agreed to participate, resulting in a response rate of $60.6 \%$. The net percent of respondents included after excluding the missing questionnaires, which represented more than $20 \%$ of the data, was $77 / 142$ or $54.22 \%$.

\section{Ethical review}

The present study's ethical approval was obtained from the Scientific Research Division's Directorate of Planning, and the General Directorate of Health-Erbil, and the study was registered under the number 638 on January $14^{\text {th }}, 2018$. The research's aims were explained to the doctors, and their verbal consent was given prior to data collection.

\section{Results}

The physicians' median age was 33.0 (interquartile range [IQR] $=12.5$; range $=25-70$ years). Of the 77 doctors who participated in the present study, more than half were males (58.4\%). Most were senior house officers (39.0\%), followed by junior house officers $(22.1 \%)$, and they worked in both the public and private sectors (62.3\%). Most respondents worked in various shifts $(53.2 \%)$ but predominantly the morning shift (35.1\%) (See Table 1).

Table 1: Baseline information of the physicians

\begin{tabular}{|c|c|c|}
\hline \multirow{2}{*}{$\begin{array}{l}\text { Physicians' characteristics }(n=77) \\
\text { Age (Year); Range: } 25.0-70.0\end{array}$} & \multicolumn{2}{|c|}{ Frequency Distribution } \\
\hline & 33.0 (median) & $\mathbf{1 2 . 5}$ (interquartile range) \\
\hline & Frequency & Percentage \\
\hline \multicolumn{3}{|l|}{ Gender } \\
\hline Male & 45 & 58.4 \\
\hline Female & 32 & 41.6 \\
\hline \multicolumn{3}{|l|}{ Job hierarchies } \\
\hline Junior House Officer & 17 & 22.1 \\
\hline Senior House Officer & 30 & 39.0 \\
\hline General Practitioner & 13 & 16.9 \\
\hline Specialist & 15 & 19.5 \\
\hline Consultant & 2 & 2.6 \\
\hline \multicolumn{3}{|l|}{ Working sector } \\
\hline Public & 29 & 37.7 \\
\hline Both public and private Sectors & 48 & 62.3 \\
\hline \multicolumn{3}{|l|}{ Working shifts } \\
\hline Morning (8 am-2 pm) & 27 & 35.1 \\
\hline Evening ( 2 pm-8 pm) & 7 & 9.1 \\
\hline Night (8 pm-8 am) & 2 & 2.6 \\
\hline Multi-shift & 41 & 53.2 \\
\hline
\end{tabular}


The doctors surveyed slightly agreed that generic drugs should be prescribed according to utility (median $[M]=5.0 ; I Q R=2.9$ ). Most of the physicians mentioned that they prescribe the drugs according to the patients' needs (75.0\%), evaluation of alternatives availability (69.0\%), consumers' perceptions of the drug cost (69.0\%), and product brand equity (60.0\%). More than half of the physicians reported that they prescribe the drugs according to corporate brand equity (51.0\%) and the importance of physicians' perceptions and recognition of need achievement (55.0\%). Close to half of them reported that they prescribe generic drugs according to the influence of opinions' leaders $(45.0 \%)$, the importance of pharma brand age $(43.0 \%)$, and actual use of drugs by consumers (49.0\%). One-third of the physicians reported that they prescribe the drugs according to the importance of consumers' attitudes towards drugs' favorability $(35.0 \%)$, consumers' intent to purchase drugs (30.0\%), and consumers' intentions and attitudes (31.0\%), see Table 2.

\begin{tabular}{|c|c|c|c|}
\hline \multicolumn{4}{|l|}{ Attitudes Items ( $n=77)$} \\
\hline The prescription of the drugs according to the: & $\begin{array}{l}\text { Median } \\
\text { (IQR) }\end{array}$ & Agree & Disagree \\
\hline Perceived utility of drugs & $5.0(2.9)$ & & \\
\hline I prescribe the drugs according to the patients' needs. & $7(2.5)$ & $58(75)$ & $10(13)$ \\
\hline I prescribe the drugs to patients according to the evaluation of alternatives availability. & $6(2.0)$ & $53(69)$ & $5(6)$ \\
\hline I prescribe the drugs according to consumer perceptions of a price. & $5(2.0)$ & $53(69)$ & $9(12)$ \\
\hline I prescribe the drugs according to product brand equity. & $5(3.0)$ & $46(60)$ & $20(26)$ \\
\hline I prescribe the drugs according to corporate brand equity. & $5(3.0)$ & $39(51)$ & $21(27)$ \\
\hline I prescribe the drugs according to opinion leaders' influence. & $4(2.0)$ & $35(45)$ & $27(35)$ \\
\hline $\begin{array}{l}\text { I prescribe the drugs according to the importance of physicians' perceptions and need } \\
\text { achievement. }\end{array}$ & $5(3.0)$ & $42(55)$ & $22(29)$ \\
\hline I prescribe the drugs according to the importance of pharma brand age in brand awareness. & $4(2.5)$ & $33(43)$ & $25(32)$ \\
\hline $\begin{array}{l}\text { I prescribe the drugs according to the importance of customers' attitudes towards drug's } \\
\text { favorability. }\end{array}$ & $4(3.0)$ & $27(35)$ & $34(44)$ \\
\hline I prescribe the drugs according to consumers' intend to purchase. & $4(3.0)$ & $23(30)$ & $36(47)$ \\
\hline I prescribe the drugs according to consumer's intentions/attitudes. & $3(3.0)$ & $24(31)$ & $41(53)$ \\
\hline I prescribe the drugs according to actual use of consumers. & $4(4.0)$ & $38(49)$ & $30(39)$ \\
\hline
\end{tabular}

\section{Table 2: Attitudes of physicians towards prescription of drugs}

The present study considered the respondents' perception of drug utility when giving prescriptions to be a dependent variable, and other attitudes toward drug prescription-taking into account demographic aspects (i.e., confounders)-were included as independent factors in a linear regression model. The analysis showed that the doctors' tendency to consider perceived drug utility differs between males and females. That is, the perceived utility is more important to males compared to females. Besides, the physicians' perceptions of need achievement $(P=0.012)$ and the doctors' attitudes toward consumers' actual drug use $(P=0.030)$ predict these physicians' perceptions of drug utility when filling out prescriptions (see Table 3). 
Table 3: Predictors of perceived utility of prescription of drugs by physicians

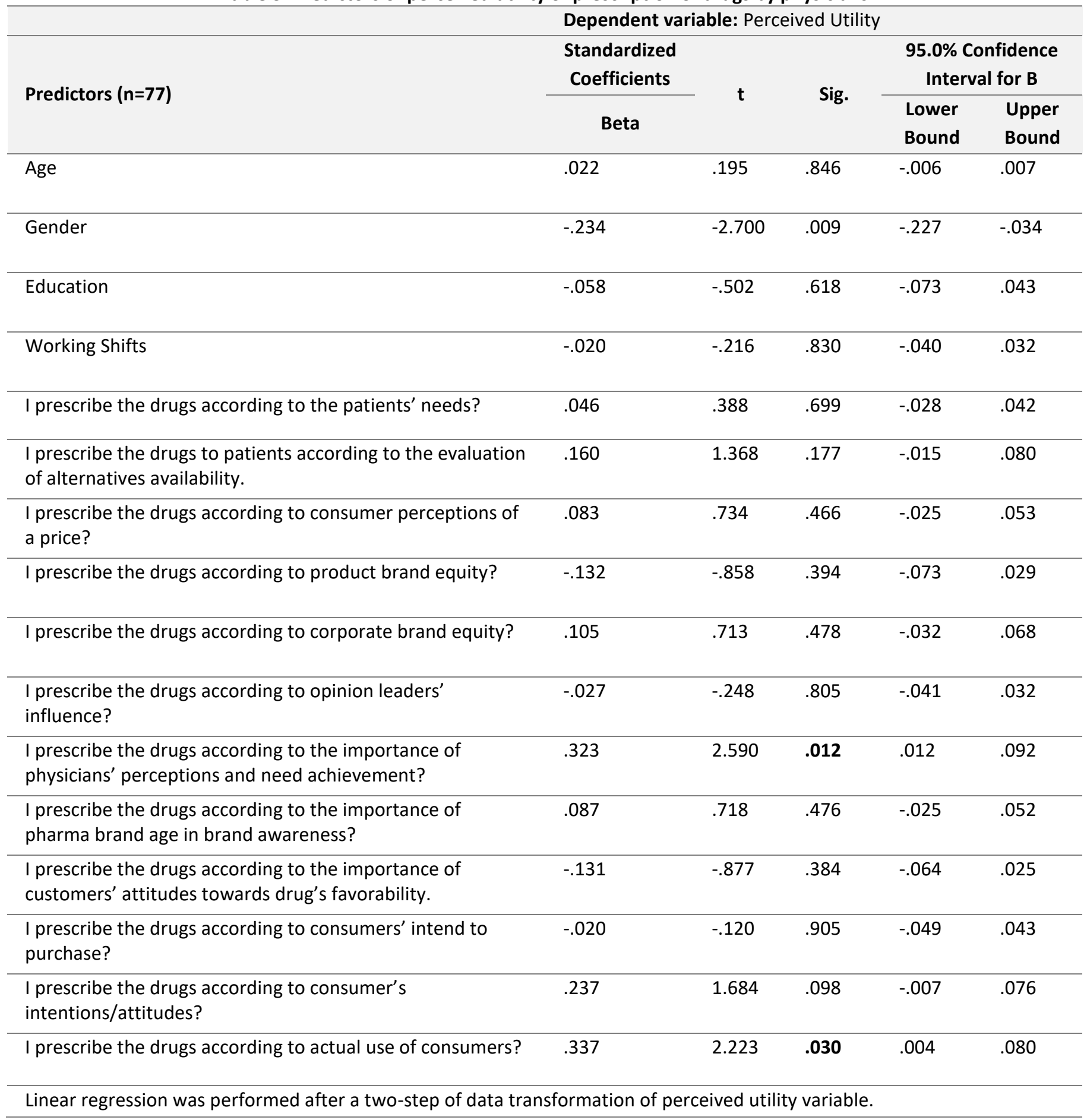

As shown in Table 4, the items of perceived utility, including drug efficacy, branded generic drug tolerability, easy availability, patient satisfaction, and physicians' on-the-job effectiveness were considered dependent variables, and the doctors' attitudes and confounders were included as independent variables in multivariate testing. The analysis revealed that males significantly more often consider branded generic drug tolerability $(P=0.049)$ and their own on-the-job effectiveness $(P=0.034)$. Similarly, junior house officers $(P=$
0.018), older doctors ( $P=0.026)$, and physicians who take into account their perceptions of need achievement $(P=0.004)$ significantly more often consider their on-the-job effectiveness when prescribing drugs. In addition, the doctors who more strongly consider need achievement $(P<0.001)$ and drug cost $(P=0.006)$ more often take into account branded generic drug tolerability. Finally, the doctors' perceptions of consumers' actual drug use predicted these physicians' perceptions of drugs' easy availability $(P<0.001)$ (see Table 4$)$. 
Table 4: Predictors of items of perceived utility in the prescription of drugs

\begin{tabular}{|c|c|c|c|c|c|}
\hline Predictors $(n=77)$ & Dependent Variables & $\begin{array}{c}\text { Mean } \\
\text { Square }\end{array}$ & $\mathbf{F}$ & Sig. & $\begin{array}{c}\text { Partial Eta } \\
\text { Squared }\end{array}$ \\
\hline \multirow[t]{2}{*}{ Gender } & Tolerability of the generic drugs & 6.087 & 4.051 & .049 & .069 \\
\hline & Effectiveness of physician job & 10.328 & 4.750 & .034 & .079 \\
\hline Job Hierarchies & The effectiveness of physician job & 7.065 & 3.249 & .018 & .191 \\
\hline Perceived Cost & Tolerability of the generic drugs & 12.207 & 8.124 & .006 & .129 \\
\hline \multirow[t]{2}{*}{ Need Achievement } & Tolerability of the generic drugs & 22.351 & 14.874 & $<.001$ & .213 \\
\hline & Effectiveness of physician job & 19.382 & 8.914 & .004 & .139 \\
\hline
\end{tabular}

Multivariate tests were performed for statistical analysis. The non-significant predictors were not shown in this table.

\section{Discussion}

The present study sought to examine the predictors of physicians' perceptions of drug utility when issuing prescriptions. The doctors surveyed agreed that drugs must be prescribed according to their utility, and the respondents also strongly agreed that prescribed drugs should be in accordance with patients' needs. The physicians' perceptions of need achievement and consumers' actual drug use were associated with doctors' perceptions of drug utility while filling out prescriptions.

The respondents' most negative attitudes were that they only slightly agreed that drugs should be prescribed according to their utility. However, the positive attitude is that they reported that they strongly agreed that they should prescribe generic drugs in accordance with patients' needs. These negative attitudes have also been detected in physicians' perceptions in other countries. Theodorou et al ${ }^{24}$ reported that many doctors do not consider generic drugs' effectiveness, safety, and efficacy to be the most important factors when prescribing drugs. The current investigation found that the factor contributing the most to the respondents' perceived drug utility is easy availability, which is strongly predicted by the doctors' perceptions of consumers' actual drug use (effect size $=0.226$ ). In addition, generic drugs tolerability is strongly predicted by physicians' perceived need achievement (effect size $=0.213$ ).

An eight-step approach to appropriate prescribing medications recommends that the patients' issues must be evaluated and clearly defined before prescribing drugs. $\underline{29}$ The physicians are respected to recognize the right of need of their patients and suggest drugs for the well-being of their patients. The relation of the physicians with pharmaceutical companies may create a conflict between the ethical professional interest and its financial self-interest. $\underline{30}$ The close link between the pharmaceutical industry and prescribing drug by doctor has been reported in Iraqi Kurdistan as well. ${ }^{12}$ The scholars reported that there is a positive association between patients and requests and prescribing drugs. $\underline{31}, \underline{32}$ It seems that this kind of association is driven by the pressure of patient. Kravitz et al ${ }^{31}$ reported that when physicians do not comply with patient requests, their patients are less satisfied with the physician practice.

We postulated that junior and older doctors and those physicians who value need achievement to consider their onthe-job effectiveness is important to keeping clients satisfied in both the public and private sectors. Junior doctors with less experience were expected to have fewer clients compared to those with higher levels of education and experience. Sanyal et al 26 also found that product brand equity, corporate brand equity, perceived cost, and opinion leaders' influence have a substantial impact on drugs' perceived utility. These factors determine the relationship between perceived drug utility and physicians' perceptions, attitudes, and need achievement.

Drugs' cost does not predict doctors' attitudes toward prescribing drugs according to their perceived utility, even though the respondents slightly agreed that price needs to be considered in drug prescription. Theodorou et al ${ }^{24}$ highlighted that cost is important to $46.6 \%$ and $51.3 \%$ of Greek and Cypriot physicians, respectively, while the cost is highly important to $16.0 \%$ and $11.4 \%$ of both groups of doctors, respectively. Drug cost in the present study only predicted generic drugs tolerability. Cost may thus be more important to patented drugs than to genetic drugs because the former is more expensive. Moreover, generic drugs' tolerability and physicians' on-the-job effectiveness are predicted by doctors' need 
achievement. Generic drugs also may not be suitable for patients under certain conditions. $\underline{33}$

One of the main factors which was associated with the perceived utility of drugs by physicians was the physicians' perceptions of the actual use of drugs by consumers in this region. The official reports from Iraq mentioned that a higher proportion of Iraqi cardiac patients (64.3\%) reported a medium/low level of adherence to their medications. The patients' beliefs about cardio-protective medications were determined to be an independent predictor of cardiac medication adherence. $\stackrel{34}{ }$ We hypothesize that the physicians may have an experience of a high non-adherence to medication among their patients, which is perceived utility is slightly important to them. Particularly, non-adherence to medicines is common in patients with chronic disease and those who prescribed preventive medications in other countries as well..$\underline{35}$

Physicians play an important role in determining whether patients need branded or generic drugs. This decision has an impact on doctors' effectiveness when prescribing drugs, which varies by gender, age, and position in job hierarchies in the region under study. The perceived cost has previously been found to hinder consumers' actual drug use. However, the present study found that drugs' cost does not affect physicians' need achievement and their perception of consumers' actual drug use. Therefore, cost most probably does not influence perceived quality as generic drugs are cheaper than branded drugs. The former is frequently prescribed by physicians in Middle Eastern countries. $\frac{11,25}{}$ Also, the cost could be important for doctors who have patients with chronic diseases. Generic drugs are also compatible in terms of quality with branded drugs. Since no system for pharmaceutical reimbursement exists in the local health system of the region covered by the present study, doctors may encounter difficulties when prescribing either expensive or cheap versions of drugs in some circumstances.

Overall, this study did not find that the availability of alternative drugs predicts drugs' perceived utility, in contrast with the literature. .6 A large number of pharmaceutical companies sell products in Iraqi Kurdistan. Therefore, patients probably do not have any difficulty finding alternative drugs. The main obstacle in the way of improvement of prescribing drug practices is that general practitioners, or family doctors do not fill the role of gatekeepers in the region's healthcare system. More specifically, the private sector's size and influence are increasing in terms of freelancers, diagnostic settings, and hospitals.

\section{Implications for research}

Researchers need to examine further Iraqi Kurdistan physicians' perceptions of generic drugs' utility in terms of consumers' actual drug use because irrational and inappropriate drug prescriptions have adverse effects on clients. In addition, we expect that the health authorities have not adequate supervision on physicians' drug prescription behaviors in this region.

\section{Strengths and limitations}

This study is one of the few investigations which was designed to examine the factors contributing to doctors' perceptions of drug utility, according to the existing literature. Another strength is that a structured questionnaire was developed specifically to serve the research's purposes. Furthermore, most previous studies have focused on analyses of a single factor, thus failing to consider many confounding factors affecting physicians' prescription behaviors.

However, this study had limitations as well. The data were collected with a self-report technique, which can introduce bias. In addition, the small sample was taken from one geographic area, making difficulties to generalize the findings to other settings in the rest of Iraq. The influence of pharmaceutical sales practices on doctors' decision making was not included in this research because pharmaceutical sales representatives are not allowed to visit the public sector in the region under study. Moreover, they play a large role in physicians' decisions about new drug prescriptions, which were not considered here. $\underline{37}, \underline{38}$ Besides, the low response rate of physicians may have an effect on findings reported in this study.

\section{Conclusions}

The present study's results suggest that doctors agree slightly that drugs should be prescribed according to their utility and concur strongly that patients' needs must be considered. The findings include that physicians' perceptions of need achievement and patients' actual drug use predict drugs' perceived utility.

Acknowledgments: The authors of the study would like to present their deep thanks to the administration of the included hospitals and the doctors who participated in the study.

Funding: The authors were only financial supporters of the study.

Conflicts of interest: There is no conflict of interest. 


\section{References}

1. Mossialos E, Walley $T$, Mrazek M. Regulating pharmaceuticals in

Europe: an overview. Regulating pharmaceuticals in Europe: striving for efficiency, equity and quality Copenhagen, European observatory on health systems and policies. 2004:1-37.

2. OECD Indicators. Health at a Glance 2011. OECD Indicators, OECD Publishing, Paris DOI: https://doi org/101787/health_glance-2015-en Accessed February. 2015;15:2016.

3. Carthy P, Harvey I, Brawn R, et al. A study of factors associated with cost and variation in prescribing among GPs. Family Practice. 2000;17(1):36-41.

4. Nicholas R, Lee $\mathrm{N}$, Roche A. Pharmaceutical drug misuse problems in Australia; Complex issues, balanced responses. National Centre for Education and Training on Addiction (NCETA): Flinders University, Adelaide; 2011.

5. Porter G, Grills N. Medication misuse in India: a major public health issue in India. Journal of Public Health. 2015;38(2):e150-e7.

6. Velo GP, Minuz P. Medication errors: prescribing faults and prescription errors. British journal of clinical pharmacology. 2009;67(6):624-8.

7. Håkonsen $\mathrm{H}$, Toverud E-L. A review of patient perspectives on generics substitution: what are the challenges for optimal drug use. GaBi J. 2012;1(1):28-32.

8. Toverud E-L, Hartmann K, Håkonsen H. A systematic review of physicians' and pharmacists' perspectives on generic drug use: what are the global challenges? Applied health economics and health policy. 2015;13(1):35-45.

9. Hassali MA, Wong ZY, Alrasheedy AA, et al. Perspectives of physicians practicing in low and middle income countries towards generic medicines: a narrative review. Health policy. 2014;117(3):297310.

10. Sharrad AK, Hassali MA, Shafie AA. Generic medicines: perceptions of physicians in Basrah, Iraq. Australasian Medical Journal (Online). 2009(8):58.

11. Shabila NP, Al-Tawil NG, Al-Hadithi TS, et al. Iraqi primary care system in Kurdistan region: providers' perspectives on problems and opportunities for improvement. BMC international health and human rights. 2012;12(1):21.

12. Abdulah DM, Perot KA. Pharmaceutical promotions and trustworthiness on new drug prescribing among physicians in public general hospitals. Journal of Hospital Administration. 2019;8(6). 13. Schumock GT, Walton SM, Park HY, et al. Factors that influence prescribing decisions. Annals of Pharmacotherapy. 2004;38(4):557-62. 14. Aikin KJ, Swasy JL, Braman AC. Patient and physician attitudes and behaviors associated with DTC promotion of prescription drugssummary of FDA survey research results. Food and Drug Administration Center for Drug Evaluation and Research. 2004;19. 15. Magzoub M, Neyaz Y, Khoja T, et al. Determinants of physicians' medication prescribing behaviour in primary care in Riyadh city, Saudi Arabia. 2011.

16. Watkins $C$, Harvey I, Carthy P, et al. Attitudes and behaviour of general practitioners and their prescribing costs: a national cross sectional survey. BMJ Quality \& Safety. 2003;12(1):29-34.

17. de Bakker DH, Coffie DS, Heerdink ER, et al. Determinants of the range of drugs prescribed in general practice: a cross-sectional analysis. BMC health services research. 2007;7(1):132.

18. Muijrers PE, Grol RP, Sijbrandij J, et al. Differences in prescribing between GPs. Impact of the cooperation with pharmacists and impact of visits from pharmaceutical industry representatives. Family Practice. 2005;22(6):624-30.
19. Nair HS, Manchanda P, Bhatia T. Asymmetric social interactions in physician prescription behavior: The role of opinion leaders. Journal of Marketing Research. 2010;47(5):883-95.

20. Bloomfield $H$, Nelson $D$, Van Ryn $M$, et al. A trial of education, prompts, and opinion leaders to improve prescription of lipid modifying therapy by primary care physicians for patients with ischemic heart disease. BMJ Quality \& Safety. 2005;14(4):258-63.

21. Lim LL, Melewar T, Sorensen T. Clinical trials: a branding opportunity? Global journal of management and business research. 2010;10(1).

22. Joseph K, Mantrala M. A model of the role of free drug samples in physicians' prescription decisions. Marketing Letters. 2009;20(1):15-29. 23. Tan N, Tay I, Ngoh A, et al. Factors influencing family physicians' drug prescribing behaviour in asthma management in primary care. Singapore medical journal. 2009;50(3):312.

24. Theodorou M, Tsiantou V, Pavlakis A, et al. Factors influencing prescribing behaviour of physicians in Greece and Cyprus: results from a questionnaire based survey. BMC health services research. 2009;9(1):150.

25. Salhia HO, Ali A, Rezk NL, et al. Perception and attitude of physicians toward local generic medicines in Saudi Arabia: A questionnaire-based study. Saudi Pharmaceutical Journal. 2015;23(4):397-404.

26. Sanyal SN, Datta SK, Banerjee AK. Factors influencing prescribing decisions among physicians: an empirical study on generic drugs. International Journal of Pharmaceutical and Healthcare Marketing. 2017;11(4):330-60.

27. Nath Sanyal S, Datta SK, Banerjee AK. Conceptualisation of branding: strategy based on the Indian pharma sector. International Journal of Pharmaceutical and Healthcare Marketing. 2013;7(2):175-98. 28. Nath Sanyal S, Datta SK. The effect of perceived quality on brand equity: an empirical study on generic drugs. Asia Pacific Journal of Marketing and Logistics. 2011;23(5):604-25.

29. Pollock M, Bazaldua OV, Dobbie AE. Appropriate prescribing of medications: an eight-step approach. Am Fam Physician.

2007;75(2):231-6.

30. Narendran R, Narendranathan M. Influence of pharmaceutical marketing on prescription practices of physicians. Journal of the Indian Medical Association. 2013;111(1):47-50.

31. Kravitz RL, Bell RA, Azari R, et al. Direct observation of requests for clinical services in office practice: what do patients want and do they get it? Archives of Internal Medicine. 2003;163(14):1673-81.

32. Mintzes B, Barer ML, Kravitz RL, et al. How does direct-to-consumer advertising (DTCA) affect prescribing? A survey in primary care environments with and without legal DTCA. Cmaj. 2003;169(5):405-12. 33. Bakthavathsalam G. Generic drugs: cost effective alternate to branded drugs. Health Admin. 2006;19(1):16-9.

34. Al-Ganmi AHA, Al-Fayyadh S, Ali MBHA, et al. Medication adherence and predictive factors in patients with cardiovascular disease: A comparison study between Australia and Iraq. Collegian. 2018.

35. Usherwood T. Encouraging adherence to long-term medication. Australian prescriber. 2017;40(4):147.

36. Rundle-Thiele S, Bennett R. A brand for all seasons? A discussion of brand loyalty approaches and their applicability for different markets. Journal of Product \& Brand Management. 2001;10(1):25-37.

37. Jones MI, Greenfield SM, Bradley CP. Prescribing new drugs: qualitative study of influences on consultants and general practitioners. Bmj. 2001;323(7309):378.

38. Prosser $\mathrm{H}$, Almond $\mathrm{S}$, Walley $\mathrm{T}$. Influences on GPs' decision to prescribe new drugs - the importance of who says what. Family practice. 2003;20(1):61-8. 